\title{
Risco para depressão entre pacientes convivendo com HIV-AIDS
}

\author{
Risk for depression among patients living with HIV-AIDS
}

Riesgo de depresión en pacientes que viven con VIH-SIDA

Amanda Cordeiro da Silva Arruda ${ }^{1 *}$, Diogenes José Gusmão Coutinho¹.

\begin{abstract}
RESUMO
Objetivo: Avaliar o risco para o desenvolvimento da depressão em pacientes com HIV/AIDS. Métodos: Tratase de uma revisão integrativa de literatura, realizada em setembro de 2020 nas seguintes bases de dados: LILACS, BDENF, na SCIELO e na BVS utilizando os seguintes Descritores em Ciências da Saúde (DeCS): "saúde mental", "depressão" e "HIV". Resultados: A AIDS é a doença crônica onde seus portadores têm risco elevado para desenvolver sintomas depressivos. Para este estudo foram localizados 583 artigos que depois de aplicados os critérios de inclusão e exclusão restaram 22 artigos e após leitura e análise minuciosa restaram 6 artigos que compuseram esse estudo. Após a descoberta da doença muitos foram os progressos científicos na tentativa de compreender e combater a epidemia mundial. Considerações finais: Foi possível perceber o quanto essa população está vulnerável a ter depressão pelo fato do estigma, preconceito pela sociedade imposto a esse grupo. Desse modo, se faz primordial políticas de enfrentamento para detectar e tratar o quanto antes o agravo a fim de não trazer prejuízos maiores para o tratamento com antirretrovirais como um todo.
\end{abstract}

Palavras-chave: Transtorno depressivo, HIV, Pacientes.

\begin{abstract}
Objective: To assess the risk for the development of depression in patients with HIV / AIDS. Methods: This is an integrative literature review, carried out in September 2020 in the following databases: LILACS, BDENF, SCIELO and the VHL using the following Health Sciences Descriptors (DeCS): "mental health", "depression" and "HIV". Results: AIDS is a chronic disease where its carriers are at high risk for developing depressive symptoms. For this study, 583 articles were found that, after applying the inclusion and exclusion criteria, 22 articles remained and after reading and in-depth analysis, there were 6 articles that made up this study. After the discovery of the disease, there was much scientific progress in trying to understand and combat the global epidemic. Final considerations: It was possible to see how vulnerable this population is to depression due to the stigma, prejudice imposed by society on this group. Thus, coping policies are essential to detect and treat the condition as soon as possible, so as not to bring greater harm to the treatment with antiretrovirals as a whole.
\end{abstract}

Key words: Depressive disorder, HIV, Patients.

\section{RESUMEN}

Objetivo: Evaluar el riesgo de desarrollo de depresión en pacientes con VIH / SIDA. Métodos: Se trata de una revisión integradora de la literatura, realizada en septiembre de 2020 en las siguientes bases de datos: LILACS, BDENF, SCIELO y la BVS utilizando los siguientes Descriptores de Ciencias de la Salud (DeCS): "salud mental", "depresión" y "VIH". Resultados: EI SIDA es una enfermedad crónica en la que sus portadores tienen un alto riesgo de desarrollar síntomas depresivos. Para este estudio se encontraron 583 artículos que, luego de aplicar los criterios de inclusión y exclusión, quedaron 22 artículos y luego de la lectura y análisis en profundidad, fueron 6 artículos que conformaron este estudio. Después del descubrimiento de la enfermedad, hubo muchos avances científicos para tratar de comprender y combatir la epidemia mundial. Consideraciones finales: Se pudo constatar la vulnerabilidad de esta población a la depresión debido al

${ }^{1}$ Faculdade Alpha, Recife - PE. *E-mail: cordeiroamanda2020@gmail.com 
estigma y prejuicio que la sociedad impone a este grupo. Así, las políticas de afrontamiento son fundamentales para detectar y tratar la afección lo antes posible, de modo que no se produzca un daño mayor al tratamiento con antirretrovirales en su conjunto.

Palabras clave: Trastorno depresivo, HIV, Pacientes.

\section{INTRODUÇÃO}

O HIV atua destruindo células específicas do sistema imunológico, os linfócitos T CD4+, tornando o organismo incapaz de combater infecções e doenças. A AIDS, que é uma manifestação clínica avançada do HIV, ataca o sistema imunológico, responsável por defender o organismo de doenças, e é alterando o DNA dessa célula que o HIV faz cópias de si mesmo e se replica em busca de outros órgãos para continuar a infecção (MUNIZ FCO, et al., 2018), caracteriza-se por um transtorno da imunidade celular. Desde 1996 o governo federal garante a distribuição de medicamentos antirretrovirais por meio do Sistema Único de Saúde (SUS) (COUTINHO MFC, et al., 2018).

O uso da terapia medicamentosa com antirretrovirais é essencial para uma melhor qualidade de vida dos portadores da enfermidade, pois reduz a possibilidade de infecções oportunistas ao suprimir a carga viral do HIV (CALDAS ACRB, et al., 2018). O êxito alcançado pelos esquemas terapêuticos promove a diminuição do número de cópias virais, o crescimento do número de linfócitos TCD4+ e a consequente recuperação da imunidade (BROJAN LEF, et al., 2020).

Na década de 90, com o objetivo de reduzir os efeitos ocasionados pela imunossupressão, foi incorporada ao tratamento a Terapia Antirretroviral (TARV) a Zidovudina (AZT). Atualmente a terapia é composta por vinte e um medicamentos que deve ser prescrita de acordo com a necessidade do paciente (SOUZA HC, et al., 2019).

Desde o ano de 1980 até junho de 2018 foram notificados aproximadamente 982.129 casos de AIDS no Brasil, sendo a prevalência dos casos maior nos homens $(68,6 \%)$ do que nas mulheres $(31,4 \%)$, o aumento das infecções pelo HIV deve-se às condutas sexuais de risco (ARAÚJO LF, et al., 2019). Trinta e cinco milhões de pessoas, em todo o mundo, viviam com o vírus da imunodeficiência humana (HIV) até o final de 2013. No mesmo ano, foram estimados em 2,1 milhões os novos casos de infecção pelo vírus HIV (SANTOS VP, et al., 2017)

Há uma preocupação do governo em oferecer infraestrutura adequada para manejo e tratamento destes pacientes. Neste contexto, surgem os Serviços de Atendimento Especializados (SAE), os quais visam atendimento multiprofissional, facilidade de acesso e de retirada de medicamentos (CALDAS ACRB, et al., 2018).

Estudos têm revelado uma relação complexa entre a infeção por HIV, neuroinflamação e comorbidades neurológicas e psiquiátricas, a doença mental pode ser consequência direta da neuropatia da infecção, complicando o curso da doença e a adesão ao tratamento (NEDELCOVYCH MT, et al., 2017). A infecção pelo HIV e o desalinho psiquiátrico apresentam complexa relação. Dentre as várias alterações psiquiátricas, frequentemente identificadas a depressão é a mais predominante (REIS RK, et al., 2011). A depressão é a alteração psiquiátrica dominante em indivíduos infectados pelo HIV (COUTINHO MFC, et al, 2018).

A adesão ao tratamento das pessoas que vivem com HIV/aids não se restringe a tomada de antirretrovirais é importante que ocorra um acompanhamento interdisciplinar dos adultos jovens que vivem com HIV/aids nos serviços de saúde (COSTA VT e MEIRELLES BHS, 2019).

No entanto, para que se alcance a eficácia terapêutica é necessário que haja adesão ao tratamento, e um dos fatores que podem dificultar é a ocorrência de transtornos mentais como ansiedade e depressão (NOGUEIRA GS e SEIDL EMF, et al., 2016). Assim, a não adesão é considerada ameaça para a efetividade do tratamento, no plano individual, e para a disseminação de resistência ao vírus, no plano coletivo, aumentando os casos de infectividade do HIV, logo o acompanhamento deve ser cuidadoso, planejado e registrado (SILVA RAR, et al., 2017). 
Conviver com o HIV, atualmente, exige mais do que somente tratar a doença, precisa lidar com problemas transdisciplinares que envolvem sintomas depressivos, discriminação e os efeitos adversos relacionados ao regime terapêutico (JESUS GJ, et al., 2017), diversos fatores podem afetar a qualidade de vida de pessoas vivendo com HIV/Aids (PVHA), incluindo aspectos físicos, bem-estar psicológico, efeitos colaterais dos antirretrovirais, sintomas relacionados ao HIV, imagem corporal, determinantes sociais, e acesso a serviços de saúde (OLIVEIRA RL, et al., 2018).

Transtornos depressivos são definidos como um conjunto de transtornos que apresentam em comum: "humor triste, vazio ou irritável, acompanhado de alterações somáticas e cognitivas que afetam significativamente a capacidade de funcionamento do indivíduo" (SILVA ML, et al., 2019).

A depressão tem causas multifatoriais, que incluem aspectos de personalidade, sociais e de relacionamentos, não podendo ser atribuída a uma causa única, aspectos como o sedentarismo, consumo excessivo de álcool, tabagismo e hábitos alimentares também têm sido relacionados à depressão (BARROSO SM, et al., 2018) e está associada à baixa adesão terapêutica, mais rápida progressão para a AIDS e morte, então é importante medir e avaliar essa população para identificar e dar suporte e apoio necessários (RODOVALHO AG, et al., 2018).

O estigma é considerado um defeito ou uma marca que caracteriza o outro, desvalorizando-o pelos estereótipos negativos, rótulos discriminantes e preconceituosos, a estigmatização ainda pode acarretar sérios prejuízos sociais e psicológicos, devido às sensações de inferioridade (CALIARI JS, et al., 2017), associaram a presença da depressão ao nível de estigma, baixo suporte social, isolamento, baixa autoestima e ainda como resultado da própria atividade viral (REIS RK, et al., 2017).

Barbosa L, et al (2019), em estudo realizado com adolescentes que convivem com HIV, fatores como doença crônica na família, falta de apoio ou separação familiar e baixa renda econômica podem trazer consequências, como sintomas de depressão, ansiedade e abandono escolar, interferindo na qualidade de vida destes, seus sintomas apresentam-se muito evidentes, pois causam alterações em quatro dimensões do comportamento do ser humano, sendo a afetiva, a comportamental, a cognitiva e a fisiológica, onde são observados humor depressivo, redução de energia, irritabilidade, apatia, agitação psicomotora, entre outros (JÚNIOR MORAIS SLA, et al., 2019).

Contudo, a depressão ainda é muito subdiagnosticada porque seus indicadores podem ser confundidos por sintomas físicos da infecção e pela terapia antirretroviral (TARV) (NOGUEIRA GS e SEIDL EMF, et al., 2016). Considerando os subdiagnósticos para a depressão nessa população em específico e que seu tratamento está associado a uma boa adesão a TARV, questiona-se: Como prevenir o surgimento da depressão em pacientes com HIV/AIDS? Tal questionamento configurou o ponto de partida para 0 desenvolvimento deste artigo. Portanto, identificar e tratar a depressão em portadores do HIV/AIDS tem importância na prevenção de comportamentos de risco e da transmissão do vírus, podendo melhorar a qualidade de vida e a adesão dos pacientes ao tratamento (OLIVEIRA ELL, et al., 2009).

Nesse contexto, o objetivo deste estudo é avaliar o risco para o desenvolvimento da depressão em pacientes com HIV/AIDS.

\section{MÉTODOS}

Trata-se de uma revisão integrativa de literatura, produzida por meio das seguintes etapas: definição da questão norteadora; estabelecimento de critérios para inclusão e exclusão de estudos; definição das informações a serem extraídas e categorização dos estudos; avaliação dos estudos incluídos; interpretação dos resultados e apresentação da revisão e síntese do conhecimento.

A pesquisa foi realizada em setembro de 2020 nas seguintes bases de dados: Literatura Latino-Americana e do Caribe em Ciências da Saúde (LILACS), Base de dados de Enfermagem (BDENF), na biblioteca virtual Scientific Eletronic Library Online (SCIELO) e na Biblioteca Virtual de Saúde (BVS). Para tanto considerou-se o cruzamento dos seguintes Descritores em Ciências da Saúde (DeCS): "saúde mental", "depressão" e "HIV". Aplicou-se o operador booleano AND como estratégia de busca entre os descritores. 
Delimitou-se como critérios de inclusão: artigos publicados na íntegra no período entre 2016 a 2020, no idioma português, de acesso gratuito e que apresentavam temática condizente com o objetivo da pesquisa. A opção por realizar a revisão no determinado período foi adotada com o intuito de acompanhar as evidências mais recentes da produção científica acerca do tema. Como critério de exclusão estabeleceu-se: os artigos duplicados nas bases de dados, sendo considerada apenas uma das repetições e que não respondessem ao objeto de pesquisa; editoriais sem caráter científico, anais de eventos científicos, resumos de pesquisas, artigos de reflexão, relatos de casos informais, capítulos de livros, dissertações, teses, reportagens e revisões sistemáticas, integrativas ou artigos sem qualidade metodológica satisfatória.

Os artigos encontrados foram lidos e avaliados quanto à sua adequação aos critérios de inclusão e exclusão. Comprovada a adequação, tiveram suas informações registradas em formulário próprio, contendo título do artigo, autores, ano da publicação, objetivo, tipo de estudo, método, resultados e conclusão.

Após a análise e interpretação dos dados, foi realizada a síntese do conhecimento obtido em tais publicações, a qual produziu resultados na forma narrativa, descrevendo achados comuns e divergências entre os estudos.

A Figura 1 demonstra as estratégias de busca e cruzamentos de descritores utilizados nas bases de dados durante o período de setembro de 2020, onde foram localizados 583 artigos. Após aplicados os critérios de inclusão e exclusão restaram 22 artigos.

Em uma nova etapa de leitura e análise dos resumos de cada artigo, e após subtração de 06 artigos que apareceram em duplicidade entre as bases de dados e 10 não condizentes com objetivo da pesquisa, totalizou-se uma amostra final de 6 artigos.

Figura 1 - Fluxograma da seleção dos estudos adaptado do Preferred Reporting Items for Systematic Reviews and Meta-Analyses (PRISMA).

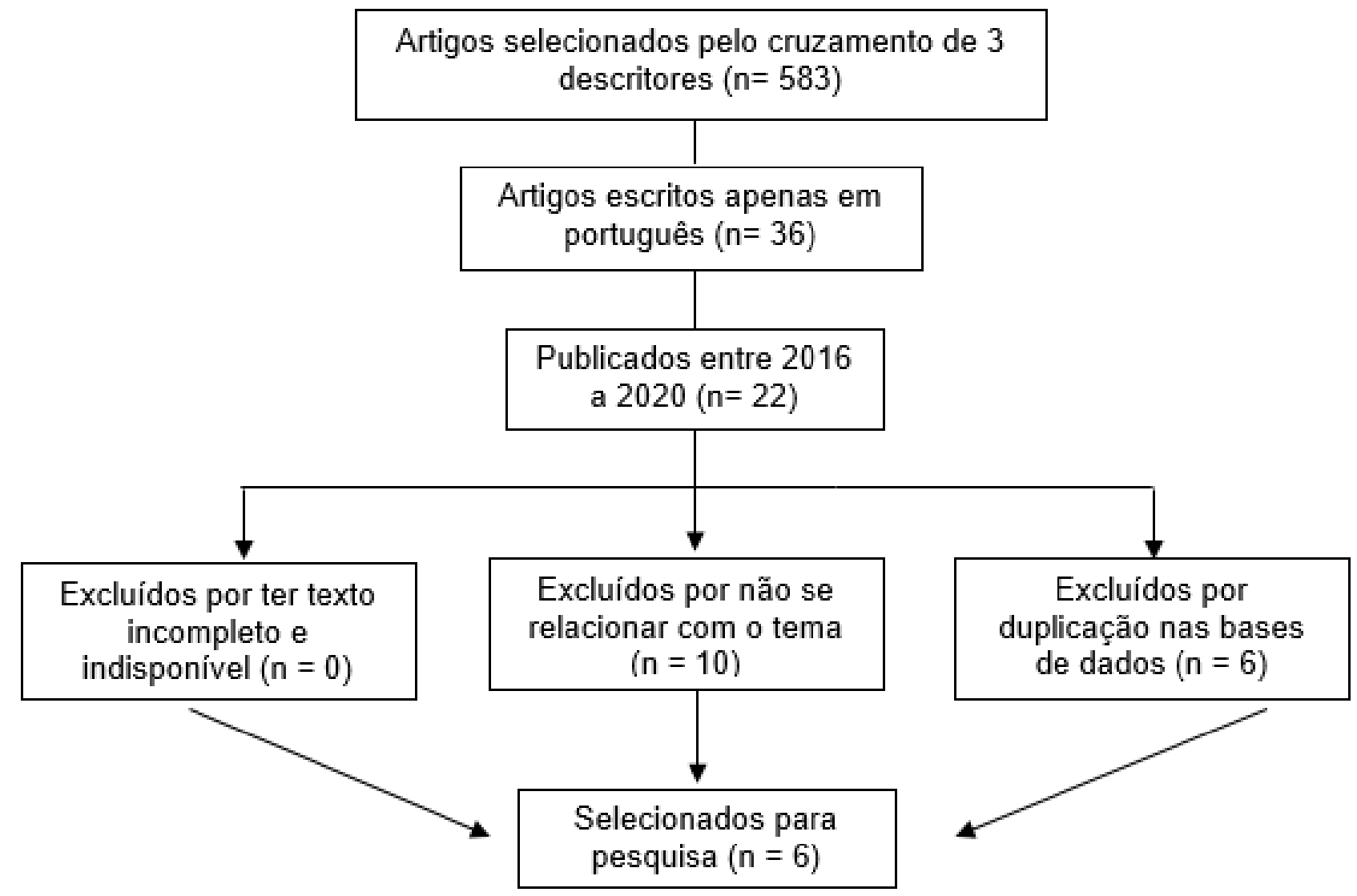

Fonte: Arruda ACS, et al., 2020. 


\section{RESULTADOS}

Os estudos sobre o risco para desenvolvimento da depressão na população que convive com HIV/AIDS (PCHIV) variam bastante em diversos aspectos como nos diferentes instrumentos utilizados, no período da coleta dos dados, nos diferentes desenhos de estudo bem como na população estudada (heterossexuais, população LGBTQIA+, idosos). O resultado do levantamento de literatura utilizado na realização dessa revisão integrativa foram encontrados e analisados 06 artigos em conformidade com o objetivo proposto deste trabalho.

Quadro 1 - Caracterização dos artigos utilizados segundo autores, ano de publicação, objetivo, metodologia e síntese dos resultados.

\begin{tabular}{|c|c|c|c|}
\hline Autores/ano & Objetivo & Metodologia & Síntese \\
\hline $\begin{array}{l}\text { MELO DS, et } \\
\text { al., } 2019\end{array}$ & $\begin{array}{l}\text { Analisar a incidência da } \\
\text { sintomatologia depressiva } \\
\text { entre lésbicas, gays, } \\
\text { bissexuais e transexuais } \\
\text { (LGBT), de dois cenários } \\
\text { distintos, e sua relação } \\
\text { com a sexualidade desses } \\
\text { indivíduos. }\end{array}$ & $\begin{array}{l}\text { Pesquisa quantitativa, mediante } \\
\text { análise estatística, realizada entre } \\
\text { os anos de } 2016 \text { a } 2018 \text {, e que } \\
\text { aplicou o Inventário de Depressão } \\
\text { de Beck - II (BDI- II) }\end{array}$ & $\begin{array}{l}\text { No HUGG foi observado } \\
\text { indicativo de depressão } \\
\text { mínima. Na EEAP, foi } \\
\text { observado indicativo de } \\
\text { depressão moderada. }\end{array}$ \\
\hline $\begin{array}{l}\text { SILVEIRA MF, } \\
\text { et al., } 2019\end{array}$ & $\begin{array}{l}\text { Avaliar as propriedades } \\
\text { psicométricas } \\
\text { questionário do } \\
\text { HIV Bref em pessoas com } \\
\text { HIV/AIDS }\end{array}$ & $\begin{array}{l}\text { O instrumento foi aplicado a } 226 \\
\text { pessoas com HIV/AIDS do Norte de } \\
\text { Minas Gerais }\end{array}$ & $\begin{array}{l}\text { Apresentou correlações } \\
\text { estatisticamente } \\
\text { significativas entre os seis } \\
\text { domínios, consistência } \\
\text { interna e reprodutibilidade } \\
\text { satisfatórias. }\end{array}$ \\
\hline $\begin{array}{l}\text { SILVA SK, et } \\
\text { al., } 2015\end{array}$ & $\begin{array}{l}\text { Verificar a associação } \\
\text { entre religiosidade e } \\
\text { indicativos de ansiedade e } \\
\text { depressão em pacientes } \\
\text { com HIV }\end{array}$ & $\begin{array}{l}\text { Estudo transversal com amostra de } \\
\text { conveniência composta de } 617 \\
\text { pessoas que vivem com HIV }\end{array}$ & $\begin{array}{lr}\text { Infere-se que } & \text { a } \\
\text { religiosidade seja benéfica } \\
\text { para a saúde mental, } \\
\text { especialmente } & \text { em } \\
\text { pacientes } & \text { com } \\
\text { sintomatologia ansiosa. }\end{array}$ \\
\hline $\begin{array}{l}\text { PATRÍCIO } \\
\text { ACFA, et al., } \\
2018\end{array}$ & $\begin{array}{lr}\text { Analisar } & \text { depressão, } \\
\text { autoestima, } & \text { expectativa } \\
\text { futura e esperança de vida } \\
\text { de pessoas com HIV/aids. }\end{array}$ & $\begin{array}{l}\text { Pesquisa transversal, com } 108 \\
\text { indivíduos vivendo com HIV/aids } \\
\text { em um hospital de referência no } \\
\text { tratamento de doenças } \\
\text { infectocontagiosas no Nordeste do } \\
\text { Brasil. }\end{array}$ & $\begin{array}{lr}1,5 \% \text { apresentaram } \\
\text { depressão leve e } 21,3 \% \\
\text { moderada; } r \text { a vida um } \\
\text { consideram a ve } \\
\text { fracasso; } 52,8 \% \text { sentem-se } \\
\text { inúteis. Medo, culpa e } \\
\text { solidão influenciam a } \\
\text { autoestima. }\end{array}$ \\
\hline $\begin{array}{l}\text { SCANAVINO } \\
\text { MDT, et al., } \\
2018\end{array}$ & $\begin{array}{lr}\text { Examinar } & a \\
\text { compulsividade } & \text { sexual } \\
\text { (CS), } & \text { ansiedade, } \\
\text { depressão } & \text { e } \\
\text { comportamento sexual de } \\
\text { risco }\end{array}$ & $\begin{array}{l}\text { Estudo realizado no Ambulatório de } \\
\text { Impulso Sexual Excessivo e } \\
\text { Prevenção de Desfechos } \\
\text { Negativos Associados ao } \\
\text { Comportamento Sexual (AISEP), } \\
\text { Instituto de Psiquiatria (IPq), } \\
\text { Hospital das Clínicas da Faculdade } \\
\text { de Medicina da Universidade de } \\
\text { São Paulo (USP) }\end{array}$ & $\begin{array}{l}\text { Em comparação com os } \\
\text { controles, os pacientes } \\
\text { ambulatoriais com ESB } \\
\text { apresentaram maior CS, } \\
\text { ansiedade e depressão, } \\
\text { que foram correlacionados. }\end{array}$ \\
\hline $\begin{array}{l}\text { BATISTA I e } \\
\text { PEREIRA H, } \\
\quad 2020\end{array}$ & $\begin{array}{l}\text { Estimar as disparidades } \\
\text { que existem ao nível da } \\
\text { saúde mental entre } \\
\text { homens mais velhos, gays } \\
\text { e bissexuais }\end{array}$ & $\begin{array}{l}\text { Foi recolhida uma amostra de } 201 \\
\text { homens mais velhos gays e } \\
\text { bissexuais que responderam a } \\
\text { Escala de Autoestima de } \\
\text { Rosenberg }\end{array}$ & $\begin{array}{l}\text { A amostra recolhida revela } \\
\text { níveis medianos de } \\
\text { autoestima e que } \\
\text { demonstra níveis de } \\
\text { somatização, depressão e } \\
\text { ansiedade inferiores à } \\
\text { média da população }\end{array}$ \\
\hline
\end{tabular}

Fonte: Arruda ACS, et al., 2020. 


\section{DISCUSSÃO}

Desde a descoberta do Vírus da Imunodeficiência Humana (HIV) muitos foram os progressos científicos na tentativa de compreender e combater a epidemia mundial (FRANCISCO FS, et al., 2016). A saúde mental de adultos jovens é uma preocupação importante e, entre os diversos transtornos mentais, a depressão é um dos mais comuns nessa etapa da vida, de 15 a $25 \%$ das pessoas podem apresentar crise depressiva pelo menos uma vez na vida (BARBOSA LNF, et al., 2020).

O transtorno mental é definido como um padrão comportamental que ocorre em um indivíduo e está associado a um risco significativo aumentado do sofrimento e/ou incapacitação em sua vida, o risco de um indivíduo apresentar o transtorno em questão é de $8 \%$ durante a sua vida (LIMA LGB, et al., 2020). A depressão afeta 121 milhões de pessoas no mundo sendo responsável pelo quarto lugar em gastos totais com doenças (SILVA ML, et al., 2019)

Na pesquisa realizada por Melo DS, et al. (2019) dos 14 participantes do primeiro cenário apenas 01 referiu "tristeza" e o justificou pelo preconceito, não pela orientação sexual e sim pelo diagnóstico de HIV, já no segundo cenário onde participaram da pesquisa 62 pacientes, 39 referiram "tristeza" decorrente da discriminação e pela sensação de não aceitação pela sociedade. É afirmada que a população LGBT apresenta vulnerabilidade relativa às questões de saúde mental, pela exposição à discriminação e ao desrespeito adicionada a expectativa de rejeição e necessidade de dissimulação de sua identidade, homens gays e bissexuais apresentarem probabilidade duas vezes maior em serem diagnosticados com depressão quando comparados com homens heterossexuais, mas nesse estudo evidenciou-se também que a própria família para $23(59 \%)$ participantes seria a fonte da tristeza.

Essa correlação entre HIV e homossexualidade é histórica e ainda hoje é marcado pelo preconceito a estas pessoas, está relacionada também com as bases morais e religiosas sobre as quais o país se formou. Acredita-se que por essa população apresentar um comportamento fora dos padrões sociais, eles são atingidos em sua maioria por agressões verbais, físicas e até psicológicas.

Importante destacar que estudos que envolvam avaliar questões de qualidade de vida precisam ser realizados por testes validados e confiáveis, No Brasil, o questionário de WHOQOL-HIV Bref mostrou-se com características satisfatórias de confiabilidade, validade de construto, validade discriminante e concorrente A versão em português do instrumento é composta por 29 itens que avaliam seis domínios da qualidade de vida relacionada à saúde (Físico, Psicológico, Nível de Independência, Relações Sociais, Ambiente e Espiritualidade) e a qualidade de vida geral. Assim foi o estudo apresentado por Silveira MF, et al. (2019), onde foi utilizado o questionário de World Health Organization Quality of Life HIV (WHOQOL-HIV Bref), juntamente com o Inventário de Depressão de Beck (BDI) em 226 pacientes onde o instrumento mostrou-se capaz de avaliar a qualidade de vida na amostra estudada.

Com os resultados de testes assim, mesmo existindo um número limitado de instrumentos para esse fim, este estudo mostrou que o uso do questionário tem se mostrado válido e confiável para obtenção desse resultado juntando a isso o enfrentamento e ações necessárias tendem a serem mais assertivas a fim de avaliar os impactos das intervenções relacionadas ao HIV

No estudo sobre a relação da prática religiosa e a saúde mental realizado por Silva SK, et al. (2016) que contou com $51,7 \%$ de pacientes do sexo feminino, onde $47 \%$ tiveram indicativo de ansiedade e apenas $34,4 \%$ indicativo de depressão demonstrou que $71,7 \%$ se declararam "ter religião", 49,5\% "ter prática religiosa" e $45 \%$ possuírem "religiosidade". Esse achado está de acordo que com as práticas religiosas há menores prevalências de sintomas depressivos e ansiosos, pois mostrou amenizar sintomas de ansiedade provenientes dessa condição de doença por propiciar sensação de bem-estar consigo mesmo e segurança, porém isso não é observado em classes sociais mais favorecidas onde os achados apresentaram o desfecho religiosidade em menor proporção.

A religiosidade pode proporcionar conforto à medida que faz o paciente se conhecer e se aceitar mais fazendo assim que sua autoestima melhore consideravelmente os estudos demonstraram que independente da doutrina, a fé mantém esses pacientes melhores, já a prática religiosa pode amenizar sintomas de 
ansiedade provenientes dessa condição. O transtorno psiquiátrico detectado com maior frequência nas pessoas soropositivas é a depressão, sendo essa, caracterizada pela perda de interesse e prazer por tudo, pelo sentimento de tristeza e baixa da autoestima (SILVA IBN, et al., 2020).

Muitas vezes as queixas psicológicas trazidas por esses pacientes são subestimadas, por não possuírem sintomas físicos os profissionais de saúde minimizam os prejuízos a longo prazo e pela falta de tratamento adequado faz com que essa população tenha elevados índices de transtornos mentais. Em estudo realizado com pacientes de um hospital de referência da cidade de João Pessoa por Patrício ACFA, et al. (2019), 108 pacientes foram entrevistados, desses, 31,5\% referiram ter depressão leve e $21,3 \%$ da forma moderada, corroborando assim com a opinião dos autores que a depressão pode dificultar a adesão ao tratamento e consequentemente aumentar a progressão da infecção, a autoestima de pessoas com HIV/aids apresenta-se prejudicada e envolve fatores que podem e devem ser revertidos, como medo, culpa e solidão, pois estão interligados a tentativas de suicídio. Estima-se ainda que até o ano de 2030 a depressão estará entre os três principais casos de doenças em todo mundo, juntamente com o HIV/aids e a doença coronariana.

Esses sentimentos parecem estar relacionados ao impacto social que o diagnóstico traz consigo além do estigma que a doença tem, e isso pode dificultar a adesão ao tratamento, o que leva a piora do quadro clínico, debilidades, reclusão, isolamento social e consequentemente ansiedade e/ou depressão, porque além de terem de lidar com o HIV, com a depressão, ainda precisam lidar com o julgamento muitas vezes vindo de pessoas preconceituosas, além de experimentarem sentimentos de desesperança pela impossibilidade de cura da doença.

Na pesquisa de Scanavino MDT, et al. (2018), sobre a relação da compulsão sexual, ansiedade e depressão 88 pacientes foram entrevistados, $41,1 \%$ se declararam gays ou bissexuais e $58 \%$ heterossexual e desses $36 \%$ eram homens heterossexuais que praticavam sexo anal e sexo anal sem preservativo com as parceiras principais, fato este preocupante pois sexo anal sem preservativo é risco elevado para contaminação de IST e HIV e por esse comportamento de risco apresentaram escores psicopatológicos mais altos, particularmente quando se envolveram em relações sexuais anais, estados negativos de humor, particularmente ansiosos e depressivos, têm sido associados à comportamento sexual excessivo. Os autores chegaram à conclusão de que a ansiedade pode estar associada ao risco sexual, porque para alguns indivíduos a excitação sexual alivia os sintomas depressivos e a depressão associada ao comportamento de risco, acredita-se que tais estados de humor negativos funcionem como gatilhos para essa população estudada.

Esses pacientes ao relatarem um comportamento sexual excessivo (compulsividade sexual) também relataram sexo vaginal e anal desprotegido e isso faz com que eles coloquem a si e a seus (suas) parceiros (as) em risco uma vez que a compulsividade sexual está ligada a ansiedade e a depressão e tais sintomatologias fazem com que se tome decisões que possam colocar em risco a sua saúde e a de terceiros.

Já no estudo realizado por Batista IC e Pereira H (2020) com homens gays e bissexuais mais velhos com ou sem HIV, a incidência encontrada no que diz respeito à sua saúde mental, demonstrou que a amostra se encontra bem equilibrada com apenas $1,98 \%$ dos entrevistados relatando ter depressão e $1,67 \%$ ansiedade, média bem abaixo do que se costuma encontrar em estudos com pessoas que não possuem HIV/aids, explicado pelos autores pelo fato da população estudada pertencer a uma classe social econômica média a alta e pela questão da idade avançada demonstrar uma resiliência e uma habilidade para lidar com os problemas superior à população em geral, uma vez que lidaram com stress durante toda a sua vida.

Provavelmente este achado se deve ao fato dessa população em específico já terem vivenciado muito e terem passado pelas mais diversas situações de pessoas que convivem com HIV, já possuírem também uma certa estabilidade seja emocional ou financeira e por acreditarem que não precisam mais "provar" nada a sociedade, pois já os aceitaram.

\section{CONSIDERAÇÕES FINAIS}

Com todos os achados desse artigo vemos que há uma grande possibilidade de pacientes que convivem com HIV/AIDS desenvolverem ao longo da vida depressão e as equipes multiprofissionais que atendem a 
esse público precisam acompanhar toda a evolução do paciente para detectar e atuar de imediato em conjunto, contribuindo assim a trazer os melhores desfechos a essa população acometida por essa condição. Vimos como limitação desse estudo a abordagem metodológica, a ampliação de campo de pesquisa poderá trazer mais abrangência de achados, aprofundando assim as questões aqui abordadas. Este estudo pode contribuir para o planejamento de ações e políticas públicas no provimento de cuidados de saúde, em especial para pacientes com sinais e sintomas de ansiedade e depressão para que possamos aumentar a qualidade de vidas desses pacientes.

\section{REFERÊNCIAS}

1. ARAÚJO LF, et al. Análise da Resiliência entre Pessoas que Vivem com HIV/AIDS: Um Estudo Psicossocial. Psicologia: teoria e pesquisa, 2019; 35: 1-10.

2. BARBOSA L, et al. Sequelas e alterações neuropsicológicas em adolescentes com HIV por transmissão vertical. Psicologia, Saúde \& Doenças, 2019; 20(2): 424-434.

3. BARBOSA LNF, et al. Ansiedade e depressão e uso de substâncias psicoativas em jovens universitários. Rev. Eletrônica Saúde Mental Álcool Drog, 2020; 16(1): 1-8.

4. BARROSO SM, et al. Solidão como variável preditora na depressão em adultos. Estudos Interdisciplinares em Psicologia, 2018; 9 (3): 26-37, dez. 2018.

5. BATISTA IC, PEREIRA H. Disparidades na saúde mental entre homens gays e bissexuais mais velhos com e sem diagnóstico de VIH. Psicologia, Saúde \& Doenças, 2020; 21(1): 53-61.

6. BROJAN LEF, et al. Uso de antirretrovirais por pessoas vivendo com HIV/AIDS e sua conformidade com o Protocolo Clínico e Diretrizes Terapêuticas, 2020; 18: 1-7.

7. CALDAS ACRB, et al. Panorama das Hospitalizações para Tratamento de HIV/AIDS e suas complicações no Brasil: um estudo retrospectivo. Convención Internacional de Salud, 2018

8. CALIARI JS, et al. Fatores relacionados com a estigmatização percebida de pessoas vivendo com HIV. Rev. Esc. Enferm. USP, 2017; 51: 1-7.

9. COSTA VT, Meirelles BHS. Adesão ao tratamento dos adultos jovens vivendo com HIV/aids sob a ótica do pensamento complexo. Texto Contexto Enferm, 2019; 28: 1-15.

10. COUTINHO MFC, et al. Tratamento antirretroviral: adesão e a influência da depressão em usuários com HIV/Aids atendidos na atenção primária. Saúde Debate, 2018; 42(116): 148-161.

11. FRANSCISCO FS, et al. Conhecimento de estudantes universitários em relação ao HIV /AIDS. J Health Sci Inst. 2016; 34(2): 69-74.

12. JESUS GJ. et al. Dificuldades do viver com HIV/Aids: Entraves na qualidade de vida. Acta Paul Enferm, 2017; 30(3): $301-7$.

13. JÚNIÖR MORAIS SLA, et al. A depressão como obstáculo para os futuros enfermeiros. Revista Nursing, 2019; 22(253): 2973-2978.

14. LIMA LGB, et al. Características de usuários com diagnóstico de Transtorno Depressivo atendidos em um Centro de Atenção Psicossocial. Rev. Eletrônica Saúde Mental Alcool Drog, 2020; 16(1): 1-9.

15. MELO DS, et al. A sintomatologia depressiva entre lésbicas, gays, bissexuais e transexuais: um olhar para a saúde mental. Rev Enferm UERJ, 2019; 27: 01-08.

16. MUNIZ FCO, et al. Pacientes críticos com HIV/AIDS: fatores associados às complicações. Repositório Bahiana, 2018; e3367.

17. NEDELCOVYCH MT, et al. The Psychiatric Impact of HIV. ACS Chem. Neurosci; 2017; 8: 1432-1434.

18. NOGUEIRA GS, SEIDL EMF. Associação entre Percepção de Doença e Ansiedade, Depressão e Autoeficácia em Pessoas com HIV/Aids. Temas em Psicologia, 2016; 24(2): 595-608.

19. NOGUEIRA LFR, et al. Transtornos Mentais Comuns estão associados a maior carga viral em Pessoas Vivendo com HIV. Saúde Debate, 2019; 43(121): 464-476.

20. OLIVEIRA RL, et al. Desnutrição e Qualidade de Vida em Pessoas Vivendo com HIV/AIDS. Revista Brasileira de Ciências da Saúde, 2018; 22(1): 65-72.

21. PATRÍCIO ACFA, et al. Depressão, autoestima, expectativa futura e esperança de vida de pessoas com HIV. Rev Bras Enferm, 2019; 72(5):1354-60.

22. REIS RK, et al. Sintomas de Depressão e Qualidade de Vida de Pessoas vivendo com HIV/aids. Rev. Latino-Am. Enfermagem, 2011; 19(4): 1-8.

23. REIS RK, et al. Avaliação dos sintomas depressivos somáticos e afetivo-cognitivos de pessoas vivendo com HIV/AIDS. Acta Paul Enferm, 2017; 30(1): 60-5

24. RODOVALHO AG, et al. Alterações de saúde mental em pessoas que vivem com HIV/AIDS. Perspectivas em Psicologia, 2018; 22(2): 26-42.

25. SOUZA HC, et al. Análise da adesão ao tratamento com antirretrovirais em pacientes com HIV/AIDS. Rev. Bras. Enferm, 2019; 72(5): 1361-9.

26. SCANAVINO MDT, et al. Compulsividade sexual, ansiedade, depressão e comportamento sexual de risco entre homens que procuram tratamento em São Paulo, Brasil. Rev. Bras. Psiquiatr, 2018; 40 (4): 424-431.

27. SILVA ML, et al. Folato e seu papel na depressão. Fag Journal of Health, 2019; 1 (2): $201-209$.

28. SILVA IBN, et al. Esperança de vida e depressão: pessoas vivendo com HIV/AIDS. R. pesq.: cuid. fundam. Online, 2020; 12: 124-129.

29. SILVA RAR, et al. Falta de adesão em pessoas vivendo com HIV: acurácia das características definidoras do diagnóstico de enfermagem. Rev. Latino-Am. Enfermagem, 2017; 25: 1-10.

30. SILVA SK, et al. Associação entre religiosidade e saúde mental em pacientes com HIV. Revista Psicologia: Teoria e Prática, 2016; 17(2): 36-51.

31. SILVEIRA MF, et al. Propriedades psicométricas do WHOQOL-HIV Bref para avaliação da qualidade de vida. PsicoUSF, 2019; 24(3): 475-487. 